\title{
RING CHROMOSOME 15; 46,XX,r(15) (p11q26) IN A GIRL
}

\author{
Hiroko FujITA and Hideo Matsumoto* \\ Department of Child Health, Faculty of Science of Living, Osaka \\ City University, Osaka, Japon \\ *Department of Legal Medicine, Osaka Medical School, Takatsuki, Japan
}

\begin{abstract}
Summary A ring chromosome 15 was found in peripheral blood cells in a girl, whose chromosome were studied because of slightly mental retardation and a short stature. Application of G-banding technique suggested that one chromosome 15 was a ring formed following breaks at bands $15 \mathrm{p} 11$ and $15 \mathrm{q} 26$.
\end{abstract}

\section{CASE REPORT}

The patient was the product of a full term uncomplicated gestation and delivery. Her birth weight was $2,100 \mathrm{~g}$, length $42 \mathrm{~cm}$, and head circumference $30.5 \mathrm{~cm}$. The father was 31 and mother 26 years of age at the time of the birth. The mother previously had had 2 normal children and no miscarriage. This 5-year-old patient was transferred to our cytogenetic clinic because of slow physical and mental development. She sat alone at 12 months and walked at 22 months. She began to speak when she was 3 years old and showed poor speech development thereafter. Since her birth she has been retarded in growth. During her infancy she suffered from recurrent pneumonia and was operated on for a ventricular septal defect.

At the age of 5 years, she measured $95 \mathrm{~cm}$ in height, and $45.6 \mathrm{~cm}$ in head circumference, which were both 2.5 standard deviations below normal. Her IQ score was 75 on WISC. Her face was expressionless but not odd-looking. Although there was slight hypertelorism, the shape of the eyes, nose and ears was normal. There was a café-au-lait spot on the right shoulder, and an operative scar on the chest. Her abdomen and extremities were normal. X-ray examinations revealed that the bone age in the wrists was slightly behind normal. Blood cell counts and chemical examinations of serum were within normal limits. Dermatoglyphic analysis showed no unusual palmar and plantar patterns.

\section{CYTOGENETIC FINDINGS}

Chromosomal studies were performed on two cultures of peripheral blood. 

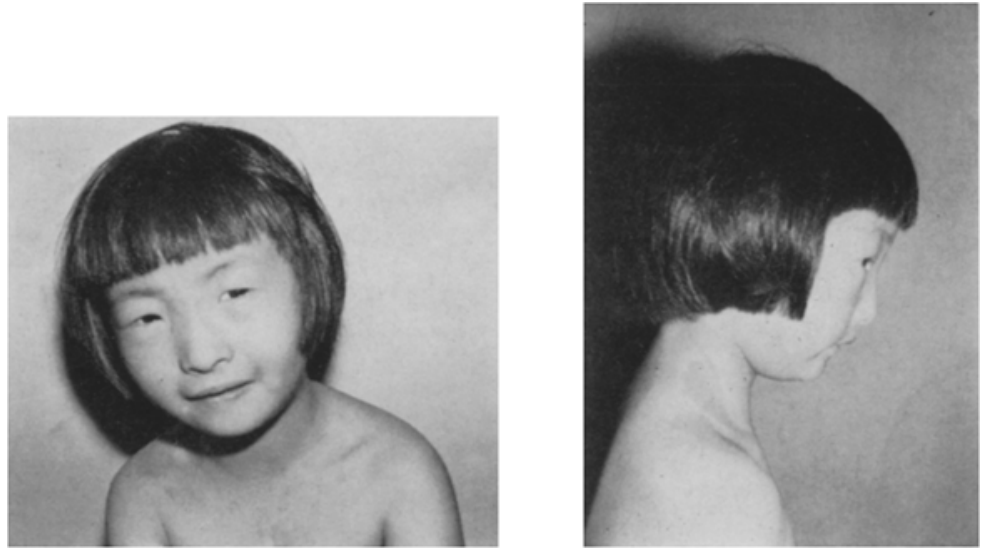

Fig. 1. The patient at five and a half years of age.

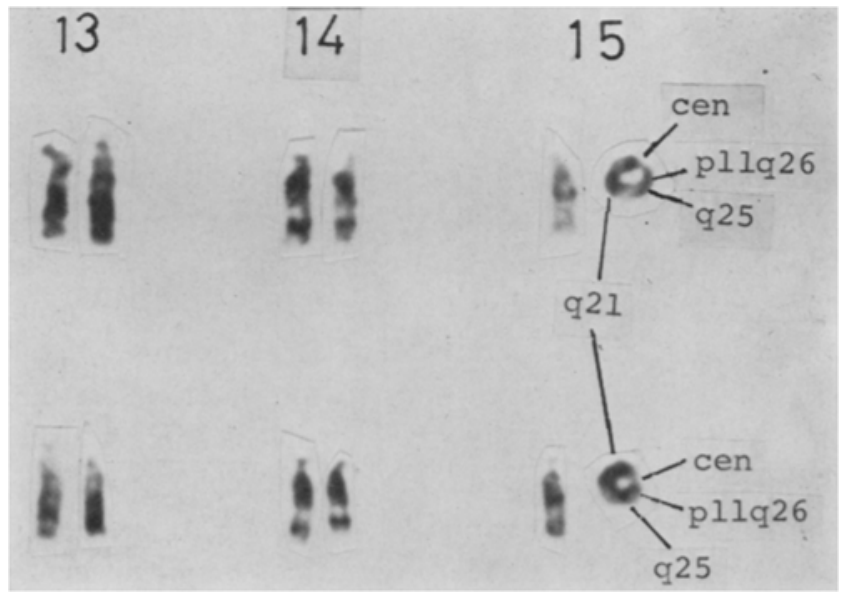

Fig. 2. G-band patterns of D-group chromosomes including of ring 15 .

Ninety-five out of 100 cells examined revealed 46 chromosomes with one ring and 3 cells showed 45 chromosomes including one ring. The two rest cells had 47 chromosomes including two rings. G-banding showed that one chromosome 15 was a ring formed following breaks at bands $15 \mathrm{p} 11$ and $15 \mathrm{q} 26$. Her karyotype was designated as $46, \mathrm{XX}, \mathrm{r}(15)$ (p11 q26).

\section{GENETIC MARKER STUDIES}

The patient and her parents were examined for genetic markers. The results are given in Table 1, indicating that the loci of Kidd, Hp and PGM have been ex- 
Table 1. Genetic marker studies on the family.

\begin{tabular}{|c|c|c|c|}
\hline Marker & Proband & Father & Mother \\
\hline $\mathrm{ABO}$ & $\mathrm{O}$ & $\mathrm{O}$ & $\mathrm{O}$ \\
\hline MNSs & MNss & MNss & MNss \\
\hline$P$ & $\mathrm{P}_{1}$ & $P_{1}$ & $\mathrm{P}_{2}$ \\
\hline $\mathrm{Rh}$ & CCDee & $\mathrm{CcDEe}$ & CCDee \\
\hline Kell & $\mathrm{kk}$ & $\mathrm{kk}$ & $\mathrm{kk}$ \\
\hline Kidd & $\mathrm{Jk}(\mathrm{a}+\mathrm{b}+)$ & $\mathrm{Jk}(\mathrm{a}-\mathrm{b}+)$ & $\mathrm{Jk}(\mathrm{a}+\mathrm{b}-)$ \\
\hline Duffy & $\operatorname{Fy}(a+b-)$ & $F y(a+b-)$ & $F y(a+b-)$ \\
\hline Lutheran & $\mathrm{Lu}(\mathrm{a}-\mathrm{b}+)$ & $\operatorname{Lu}(a-b+)$ & $\operatorname{Lu}(a-b+)$ \\
\hline Lewis & $\operatorname{Le}(a-b+)$ & $\operatorname{Le}(a-b+)$ & $\operatorname{Le}(a+b-)$ \\
\hline $\mathrm{Hp}$ & $2-1$ & $2-1$ & $2-1$ \\
\hline Tf & $\mathrm{C}$ & $\mathrm{C}$ & $\mathrm{C}$ \\
\hline $\mathrm{Gc}$ & 2 & $2-1$ & $2-1$ \\
\hline $\mathrm{Gm}$ & ag & axg & ag \\
\hline Inv & $\operatorname{Inv}(a-b+)$ & $\operatorname{Inv}(a+b+)$ & $\operatorname{Inv}(a-b+)$ \\
\hline $\mathrm{AcP}$ & B & B & B \\
\hline PGM & $2-1$ & 2 & 1 \\
\hline ADA & 1 & 1 & 1 \\
\hline 6-PGD & A & $\mathrm{A}$ & A \\
\hline EsD & 1 & 1 & 1 \\
\hline s-GPT & 1 & 1 & 1 \\
\hline s-GOP & 1 & 1 & 1 \\
\hline PHI & 1 & 1 & 1 \\
\hline LDH & 1 & 1 & 1 \\
\hline GLO & 2 & 2 & $2-1$ \\
\hline UMPK & 1 & 1 & 1 \\
\hline
\end{tabular}

cluded from the deleted segment of chromosome 15. Blood grouping tests failed to suggest localization of a genetic locus on the chromosome.

\section{DISCUSSION}

Seven patients with $\mathrm{r}(15)$ have been described to date, using autoradiography in 2 cases and banding methods in 5 cases.

Phenotypic observations on 8 patients with $\mathrm{r}(15)$ including the present case are listed in Table 2. All cases share a low birth weight, short stature and small head circumference. On the other hand, there are few concordant dysmorphia in the cranio-facial proportion and visceral malformations. Backwardness of psychomotor development is moderate in all but two cases. The normal patient described by Forabosco et al. (1972) should be subjected to a follow up study for future development, as the patient was only 16 months of age. The patient described by Stoll et al. (1975) showed severe mental retardation. She was known to have a chronic hematoma of unknown origin complicated by external hydrocephalus. Besides this, her karyotype was derived from two cell lines, which were of $46, \mathrm{XX}, \mathrm{r}(15)$ and $45, \mathrm{XX},-15$. One could suppose that her serious retardation may have been caused by the brain disorder in addition to this cytologically monosomic condition. 


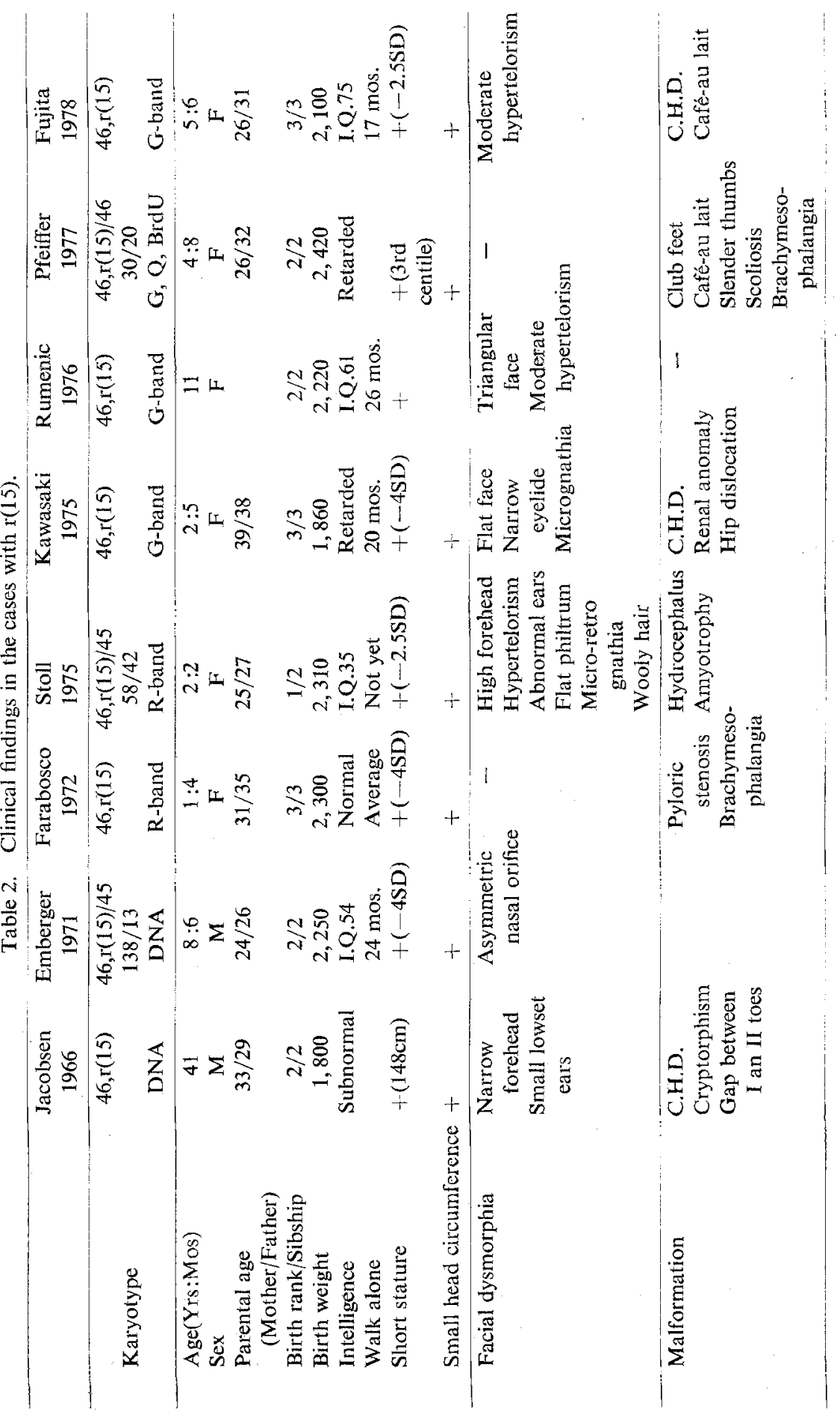


Concerning genetic markers and break points there is no investigation in the previous reports on $\mathrm{r}(15)$. In the present case, the results of blood group studies show no evidence of relationship with the deleted chromosome. The amount of genetic material lost must be small, as most of the bands could be seen in the ring chromosome. The relatively minor malformations and moderate retardation also support the presumption that the patient has a very small defect of chromosome 15 .

\section{REFERENCES}

Emberger, J.M., Rossi, D., Jean, R., Bonnet, H., and Dumas, R. 1971. Etude d'une observation de chromosome du group 13-15 en anneau (46,XY,15r). Humangenetik 11: 295-299.

Farabosco, A., Dutrillaux, B., Vazzoler, G., and Lejeune, J. 1972. Chromosome 15 en anneau: r(15). Identification par dénaturation ménagée. Ann. Génét. 15: 267-270.

Jacobsen, P. 1966. A ring chromosome in the 13-15 group associated with microcephalic dwarfism, mental retardation and emotional immaturity. Hereditas 55: 188-191.

Kawasaki, T., Kamimae, A., Maeda, J., Shinohara, T., and Tomita, H. 1975. A case with No. 15 ring chromosome (Japanese). J. Pediat. Practice. 38 : 544.

Pfeiffer, R.A., Dhadial, R., and Lenz, W. 1977. 46,XX/46,XX,r(15) mosaicism, Report of a case. J. Med. Genet. 14: 63-65.

Rumenić, Lj., Joksimović, I., and Anaf, M. 1976. Ring chromosome 15 in child with a minor dysmorphism of phenotype. Hum. Genet. 33: 187-188.

Stoll, C., Juif, J.G., Luckel, J.C., and Lausecker, C. 1975. Ring chromosome 15: r(15). Identification by $\mathrm{R}$ banding. Humangenetik 27: 259-262. 